\title{
Sage weed (Salvia plebeia) extract antagonizes foam cell formation and promotes cholesterol efflux in murine macrophages
}

\author{
SIN-HYE PARK, JUNG-LYE KIM, MIN-KYUNG KANG, JU-HYUN GONG, SEON-YOUNG HAN, \\ JAE-HOON SHIM, SOON SUNG LIM and YOUNG-HEE KANG
}

Department of Food and Nutrition, Hallym University, Chuncheon 200-702, Republic of Korea

Received May 21, 2012; Accepted July 27, 2012

DOI: $10.3892 /$ ijmm.2012.1103

\begin{abstract}
Lipid-laden peripheral tissue cells release cholesterol to an extracellular acceptor such as high-density lipoprotein (HDL). Foam cells are formed at the first stage of atherosclerosis development. This study investigated whether sage weed (Salvia plebeia) extract (SWE) influences cholesterol handling of J774A1 murine macrophages. A murine macrophage cell line, J774A1, was used in this study. Oxidized low-density lipoproteins (LDL) treatment was used for foam cell formation, which was confirmed using Oil red $\mathrm{O}$ staining. The oxidized LDL uptake and cholesterol efflux from lipid-laden foam cellassociated proteins were detected by western blot analysis. Also, transcriptional levels of these associated genes were examined using reverse transcription-PCR. Also, cholesterol efflux was measured using NBD-cholesterol efflux assay. Non-toxic $\mathrm{SWE}$ at $\geq 10 \mu \mathrm{g} / \mathrm{ml}$ attenuated scavenger receptor (SR)-B1 expression of macrophages induced by oxidized LDL for $6 \mathrm{~h}$, which was achieved at its transcriptional levels. Consistently, SWE suppressed oxidized LDL-stimulated cellular lipid accumulation and foam cell formation due to downregulated SR-B1. SWE upregulated the protein expression and mRNA levels of ATP-binding cassette transporter A1 (ABCA1) and ATP-binding cassette transporter G1 (ABCG1) in lipid-laden foam cells, both responsible for cholesterol efflux. In addition, SWE promoted apolipoprotein $\mathrm{E}$ (apoE) secretion from oxidized LDL-induced foam cells. Cholesterol efflux was enhanced by $\geq 10 \mu \mathrm{g} / \mathrm{ml} \mathrm{SWE}$ most likely through the induction of ABCA1 and ABCG1 and the secretion of apoE. Although $10 \mu \mathrm{M}$
\end{abstract}

Correspondence to: Dr Young-Hee Kang, Department of Food and Nutrition, Hallym University, Chuncheon 200-702, Republic of Korea E-mail: yhkang@hallym.ac.kr

Abbreviations: ABCA1, ATP-binding cassette transporter A1; ABCG1, ATP-binding cassette transporter G1; apoE, apolipoprotein E; LDL, low-density lipoproteins; SR, scavenger receptor; SWE, sage weed methanol extract

Key words: apolipoprotein E, ATP-binding cassette transporter, cholesterol efflux, homoplantaginin, oxidized low-density lipoproteins, sage weed extract, scavenger receptor homoplantaginin, a compound mainly present in sage weeds, did not influence cellular expression of ABCA1 and ABCG1, it suppressed oxidized LDL-enhanced SR-B1 induction and foam cell formation. These results demonstrate that SWE antagonized oxidized LDL uptake and promoted cholesterol efflux in lipidladen macrophages. Therefore, SWE may serve as a protective therapeutic agent against the development of atherosclerosis.

\section{Introduction}

Oxidized low-density lipoproteins (LDL) uptake is a key initial event in atherogenesis. Foam cell formation plays a critical role in the development of atherosclerosis. Oxidized LDL is taken up by several receptors, such as scavenger receptor (SR) class A (SR-A), SR-B1 (CD36), and macrophage CD68 (1). Macrophage $\mathrm{SR}-\mathrm{B} 1$ is the membrane receptors responsible for oxidized LDL uptake and facilitates the intracellular lipid accumulation (2). After oxidized LDL is taken up by macrophages, oxidized LDL cholesterol is degraded to oxysterols or free cholesterols in the lysosomes (3). The resulted oxysterols influence the formation of atherosclerotic plaques and are thought to have a central role in promoting atherogenesis (4). It has been speculated that oxysterols may represent the most toxic form of oxidized lipids in LDL (5). Thus, potential agents blunting oxidized LDL uptake leading to production of oxysterols are considered antiatherogenic. However, the underlying mechanisms by which the agents antagonize oxidized LDL uptake and oxysterol formation by diverse stimulators remain to be elucidated.

The removal of oxidized lipids from artery wall is arbitrated by reverse cholesterol transport, the process involving the membrane proteins of ATP-binding membrane cassette transport protein $\mathrm{A} 1$ (ABCA1) and ATP-binding cassette transporter G1 (ABCG1) (6,7). ABCA1 is involved in the exporting of cholesterol and phospholipids from peripheral cells to lipid-poor apolipoprotein A1 (apoA1) to generate precursors for HDL particles $(6,8)$. ABCG1 mediates oxysterol efflux from oxidized LDL-loaded macrophages, and the exported oxysterol by ABCG1 pathway can be selectively taken up by hepatocytes (7). Accordingly, ABCA1 and ABCG1 play a pivotal role in encumbering atherogenesis by promoting the efflux of cholesterol and oxysterols. Macrophages secrete high levels of apoE and cholesterol efflux from macrophages to apoE has been shown to decrease foam cell formation and prevent atherosclerosis (9). Furthermore, a recent study has 
shown a novel function of apoE as a significant determinant of cholesterol efflux in macrophages (10). ApoE associated with ApoB-carrying lipoproteins plays an upregulatory role on ABCA1 expression via induction of Sp1.

Sage weed (Salvia plebeia R. Br.) is an annual or biennial, hairy herb broadly distributed in many countries including China, India, Iran and Australia. Sage weed has long been used as a folk medicine in Asia and its medicinal properties are being more seriously investigated (11). Crude extract of Salvia plebeia exhibited antioxidant activity, and antioxidant compounds were isolated and identified as royleanonic acid, hispidulin and eupatorin (11). The ethanol extract of Salvia plebeia possess anti-inflammatory and anti-angiogenic, anti-nociceptive and antioxidant activities (12). Antioxidative activity and nitrite scavenging ability were observed in methanol extract from Salvia plebeia (13). However, there are no reports demonstrating anti-atherogenic activity of sage weed extract and its constituents.

Based on literature evidence that manipulating cellular cholesterol flux of peripheral cells and macrophages can be antiatherogenic, this study hypothesized that sage weed methanol extract (SWE) improved macrophage cholesterol handling in oxidized LDL-loaded macrophages. To test this hypothesis, this study elucidated oxidized LDL uptake and cholesterol efflux in J774A1 murine macrophages treated with submicromolar SWE and its components of homoplantaginin and hispidulin. The aims of this study were to investigate the pathways mediating the removal of oxysterols and cholesterol from oxidized LDL-loaded macrophages. SR-B1 induction was measured for oxidized LDL uptake, and ABCA1 and ABCG1 expression was determined for apoE-mediated cholesterol efflux in a lipid-laden macrophages.

\section{Materials and methods}

Materials. Dulbecco's modified Eagle's medium (DMEM)chemicals, fatty acid-free bovine serum albumin (BSA) and Oil red O were provided by Sigma-Aldrich Chemical (St. Louis, MO), as were all other reagents, unless specifically stated otherwise. Fetal bovine serum and penicillin-streptomycin were obtained from Lonza (Walkersville, MD). SR-B1 antibody was supplied by Santa Cruz Biotechnology (Santa Cruz, CA). ABCA1 and ABCG1 antibodies were purchased from Novus Biologicals (Littleton, CO). Apolipoprotein (apo) E antibody was obtained from Abcam (Cambridge, UK). $\beta$-actin antibody was provided from Sigma Chemicals. Horseradish peroxidase-conjugated goat anti-rabbit IgG and rabbit anti-mouse IgG were supplied by Jackson Immuno Research Laboratory (West Grove, PA). Homoplantaginin and hispidulin were supplied by Shanghai Tauto Biotech Co., Ltd. (Shanghai, China).

Preparation of SWE. Sage weeds (Salvia plebeia R.Br.) were purchased from Dae Kwang Herb (Chuncheon, Korea). The voucher specimen (RIC-22) was deposited at Regional Innovation Center (Hallym University, Chuncheon, Korea). The dried whole parts of sage weeds were pulverized and extracted with $100 \%$

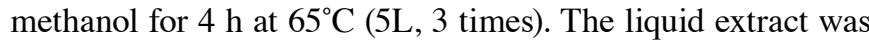
evaporated in vacuo to give crude SWE. In the experiments, SWE, homoplantaginin and hispidulin were dissolved in dimethyl sulfoxide (DMSO) for live culture with cells; its final culture concentration was $\leq 0.1 \%$.
Preparation and oxidation of human plasma LDL. Human plasma LDL was prepared by a discontinuous density gradient ultra-centrifugation as previously described (14). Pooled human normolipidemic plasma LDL fraction was dialyzed overnight against $0.154 \mathrm{mM} \mathrm{NaCl}$ and $0.01 \%$ EDTA (pH 7.4) at $4^{\circ} \mathrm{C}$ and used within 4 weeks. Protein concentration of the plasma LDL fraction was measured by the Lowry method (15), and the concentrations of triacylglycerol, total cholesterol and phospholipids were determined using diagnostic kits (Asan Pharmaceuticals, Hwasung, Korea).

Oxidized LDL was prepared by incubating LDL fraction with $10 \mu \mathrm{M} \mathrm{CuSO}^{4}\left(\mathrm{Cu}^{2+}\right)$ in $\mathrm{F}-10$ medium at $37^{\circ} \mathrm{C}$ for $24 \mathrm{~h}$. The LDL oxidation was routinely checked using TBARS concentration and eletrophoretic mobility assay (16). Aliquots of oxidized LDL were run on a $0.8 \%$ agarose eletrophoresis gel in barbital buffer ( $\mathrm{pH}$ 8.6) to measure eletrophoretic mobility. Gel photographs were obtained using a Polaroid film (Polaroid, Wayland, MA).

Cell culture. The macrophage-like cell line J774A1 (mouse histocytic lymphoma cells) were grown in DMEM supplemented with $10 \% \mathrm{FBS}$ at $37^{\circ} \mathrm{C}$ in a humidified atmosphere of $5 \% \mathrm{CO}_{2}$ in air. Macrophages were pre-treated with 1-20 $\mu \mathrm{g} / \mathrm{ml} \mathrm{SWE}, 10 \mu \mathrm{M}$ homoplantaginin, or $10 \mu \mathrm{M}$ hispidulin and exposed to $50 \mu \mathrm{g} / \mathrm{ml}$ cholesterol-oxidized LDL for various times. For the lipid uptake, macrophages were incubated in DMEM supplemented with $0.4 \%$ fatty acid-free BSA.

Lipid uptake. Oil red $\mathrm{O}$ staining was performed to detect foam cells of macrophages. Oil red $\mathrm{O}$ is a fat-soluble diazo dye staining neutral triglycerides and some lipoproteins (2). J774A1 cells cultured with $50 \mu \mathrm{g} / \mathrm{ml}$ oxidized LDL were washed with phosphate buffered saline (PBS) containing $0.05 \%$ Tween-20, and fixed in $4 \%$ ice-cold formaldehyde for $1 \mathrm{~h}$. Subsequently, $0.5 \%$ oil red $\mathrm{O}$ dissolved in 60\% 2-propanol was added to cells for $1 \mathrm{~h}$. After mounting with aqueous mounting medium, images were obtained by using an optical microscope. Oil red $\mathrm{O}$ staining was quantified by dissolving stained cells in $100 \%$ isopropanol with a spectrophotometer at $\lambda / \mathrm{nm}=490$.

Western blot analysis. Western blot analysis was performed using whole cell extracts from J774A1 macrophage as previously described (17). Cells were lysed in a lysis buffer containing $1 \% \beta$-mercaptoethanol, $1 \mathrm{M} \beta$-glycerophosphate, $0.1 \mathrm{M} \mathrm{Na}_{3} \mathrm{VO}_{4}, 0.5 \mathrm{M} \mathrm{NaF}$ and protease inhibitor cocktail. Equal protein amounts of cell lysates and equal volumes of culture media were electrophoresed on 6-12\% SDS-PAGE and transferred onto a nitrocellulose membrane. After blocking non-specific binding with 5\% skim milk for $3 \mathrm{~h}$, the membrane was incubated overnight at $4^{\circ} \mathrm{C}$ with polyclonal rabbit antibodies of SR-B1, ABCA1, ABCG1 and apoE. After three washes with Tris-buffered saline-Tween-20, the membrane was incubated for $1 \mathrm{~h}$ with a goat anti-rabbit IgG or a rabbit anti-mouse IgG conjugated to horseradish peroxidase (HRP). The individual protein level was determined using immobilon western chemiluminescent horseradish peroxidase substrate (Millipore Corp., Billerica, MA) and Agfa X-ray film (Agfa-Gevaert, Belgium). Incubation with monoclonal mouse $\beta$-actin antibody was also performed for comparative controls. 
A
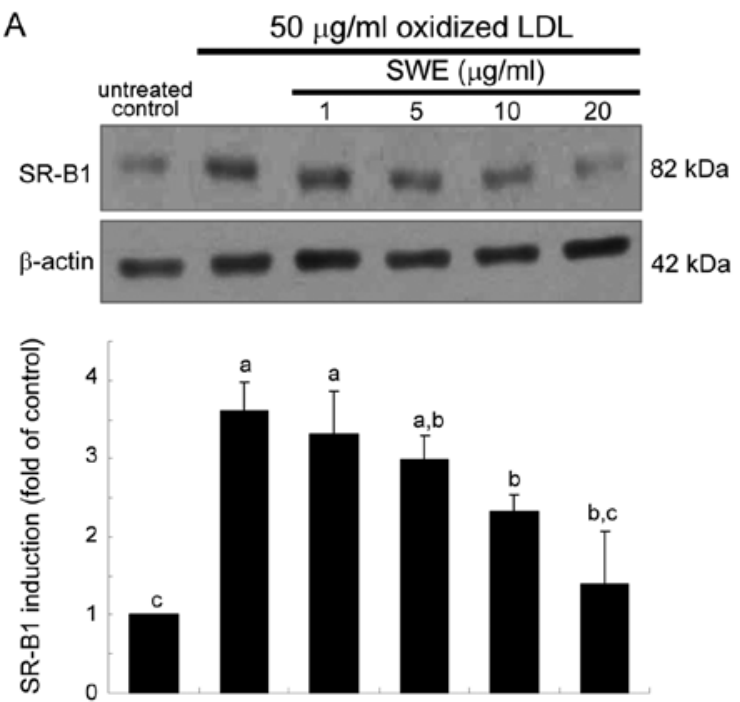

B

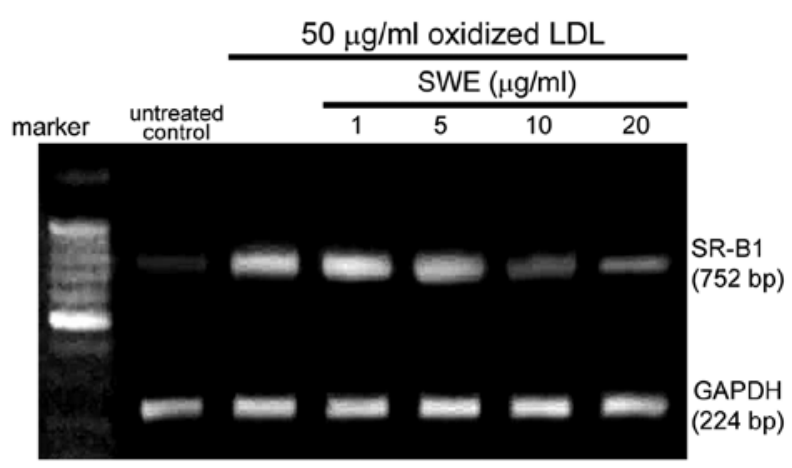

Figure 1. Inhibition of oxidized LDL induction of SR-B1 expression by SWE (A). J774A1 macrophages were treated with $50 \mu \mathrm{g} / \mathrm{ml}$ oxidized LDL for $6 \mathrm{~h}$ in the absence and presence of $1-20 \mu \mathrm{g} / \mathrm{ml}$ SWE. Total cell lysates were subjected to western blot analysis with a primary antibody against SR-B1. $\beta$-actin was used as an internal control. Quantitative RT-PCR analysis (B) showing transcriptional levels of SR-B1 in SWE-treated and oxidized LDL-stimulated macrophages for $2 \mathrm{~h}$. GAPDH was used as a housekeeping gene for the co-amplification with SR-B1. Data are mean \pm SEM, $n=3$. Values in bar graphs not sharing a same letter indicate significant different at $\mathrm{P}<0.05$.

Quantitative RT-PCR analysis. Following culture protocols, total RNA was isolated from J774A1 macrophages using a commercially available TRIzol reagent kit (Molecular Research Center, Cincinnati, OH). The RNA (5 $\mu \mathrm{g})$ was reverse transcribed with $200 \mathrm{U}$ of reverse transcriptase (Promega Corp., Madison, WI) and $0.5 \mathrm{~g} / \mathrm{l}$ oligo-(dT) $)_{15}$ primer (Bioneer, Korea). RT-PCR analysis was also performed for semi-quantifying the levels of mRNA transcripts of SR-B1, ABCA1 and ABCG1. The PCR conditions for SR-B1 [5'-ATG GGC CAG CGT GCT TTT ATG A-3' (forward), 5'-AAC CAC AGC AAC GGC AGA ACT A-3' (reverse, 752 bp)] and ABCA1 [5'-AGC TGC CCC ATC ATG TAA AG-3' (forward), 5'-GGG AGA AGA GCG TGC TAA TG-3' (reverse, $580 \mathrm{bp}$ ) were $94^{\circ} \mathrm{C}$ (3 min), and 30 cycles at $94^{\circ} \mathrm{C}(30 \mathrm{sec}), 60^{\circ} \mathrm{C}(45 \mathrm{sec})$ and $72^{\circ} \mathrm{C}(45 \mathrm{sec})$. Moreover, the condition for ABCG1 [5'-CCA AGT GGT GTC TCT GAT GA-3' (forward), 5'-CTG AGG AAG GTC CTC TTG AA-3' (reverse, $450 \mathrm{bp})]$ was $94^{\circ} \mathrm{C}(3 \mathrm{~min})$, and 28 cycles at $94^{\circ} \mathrm{C}(30 \mathrm{sec}), 55^{\circ} \mathrm{C}$ (45 sec) and $72^{\circ} \mathrm{C}(45 \mathrm{sec})$. The housekeeping gene GAPDH [5'-AAC TTT GGC ATT GTG GAA GGG-3' (forward), 5'-GAC ACA TTG GGG GTA GGA ACA C-3' (reverse, 224 bp)] was used for an internal normalization for the co-amplification with the respective gene.

Cholesterol efflux assay. J774A1 macrophages were treated with $1-20 \mu \mathrm{g} / \mathrm{ml} \mathrm{SWE}$ for $12 \mathrm{~h}$ and then equilibrated with $1 \mu \mathrm{g} / \mathrm{ml} 3$-dodecanoyl-NBD-labeled cholesterol (Cayman Chemical, Ann Arbor, MI) for additional $6 \mathrm{~h}$. Cells exposed to NBD-labeled cholesterol were washed with PBS and incubated in DMEM for $6 \mathrm{~h}$. The fluorescence-labeled cholesterol released from cells into medium for $6 \mathrm{~h}$ was detected at wavelength range $\lambda=485-538 \mathrm{~nm}$ by using a fluorometer. Cholesterol efflux was expressed as percent fluorescence in medium relative to total fluorescence.

Enzyme-linked immunosorbent assay (ELISA). Following culture protocols, culture media were collected to measure
HDL formation by using sandwich ELISA kits (Uscn Life Science Inc., Wuhan, China). After reacting to collected media on microtiter plate, wells pre-coated with a biotinconjugated antibody specific to HDL, avidin-conjugated to HRP was added to microplate wells and incubated. The TMB substrate solution was added to wells for detecting color change and the enzyme-substrate reaction was terminated by the addition of $3 \mathrm{~N}$ sulphuric acid solution. The color change was measured spectrophotometrically at $\lambda=450 \mathrm{~nm}$.

Data analysis. The results are presented as mean \pm SEM. Statistical analyses were conducted using the Statistical Analysis Statistical software package version 6.12 (SAS institute, Cary, NC). One-way ANOVA was used to determine the inhibitory effects of SWE on the cholesterol handling of macrophages. Differences among the treatment groups were analyzed with Duncan's multiple range test and were considered to be significant at $\mathrm{P} \leq 0.05$.

\section{Results}

Suppression of $S R-B 1$ expression by $S W E$. It has been shown that the uptake of oxidized LDL require SR induction in macrophages $(1,2)$. As expected, oxidized LDL hastened SR-B1 expression rapidly within $2 \mathrm{~h}$, which was sustained up to $8 \mathrm{~h}$ (data not shown). When oxidized LDL was treated for $6 \mathrm{~h}$, the SR-B1 expression diminished in a dose-dependent manner due to the presence of 1-20 $\mu \mathrm{g} / \mathrm{ml} \mathrm{SWE}$ (Fig. 1A). This study investigated whether the suppression of SR-B1 induction by SWE was achieved at its transcriptional level. Quantitative RT-PCR data revealed that $\geq 10 \mu \mathrm{g} / \mathrm{ml}$ SWE lowered oxidized LDL-elevated SR-B1 mRNA level of macrophages (Fig. 1B). It should be noted that treating macrophages with oxidized LDL markedly elevated their SR-B1 mRNA level within $2 \mathrm{~h}$ (data not shown). 
A

$50 \mu \mathrm{g} / \mathrm{ml}$ oxidized LDL

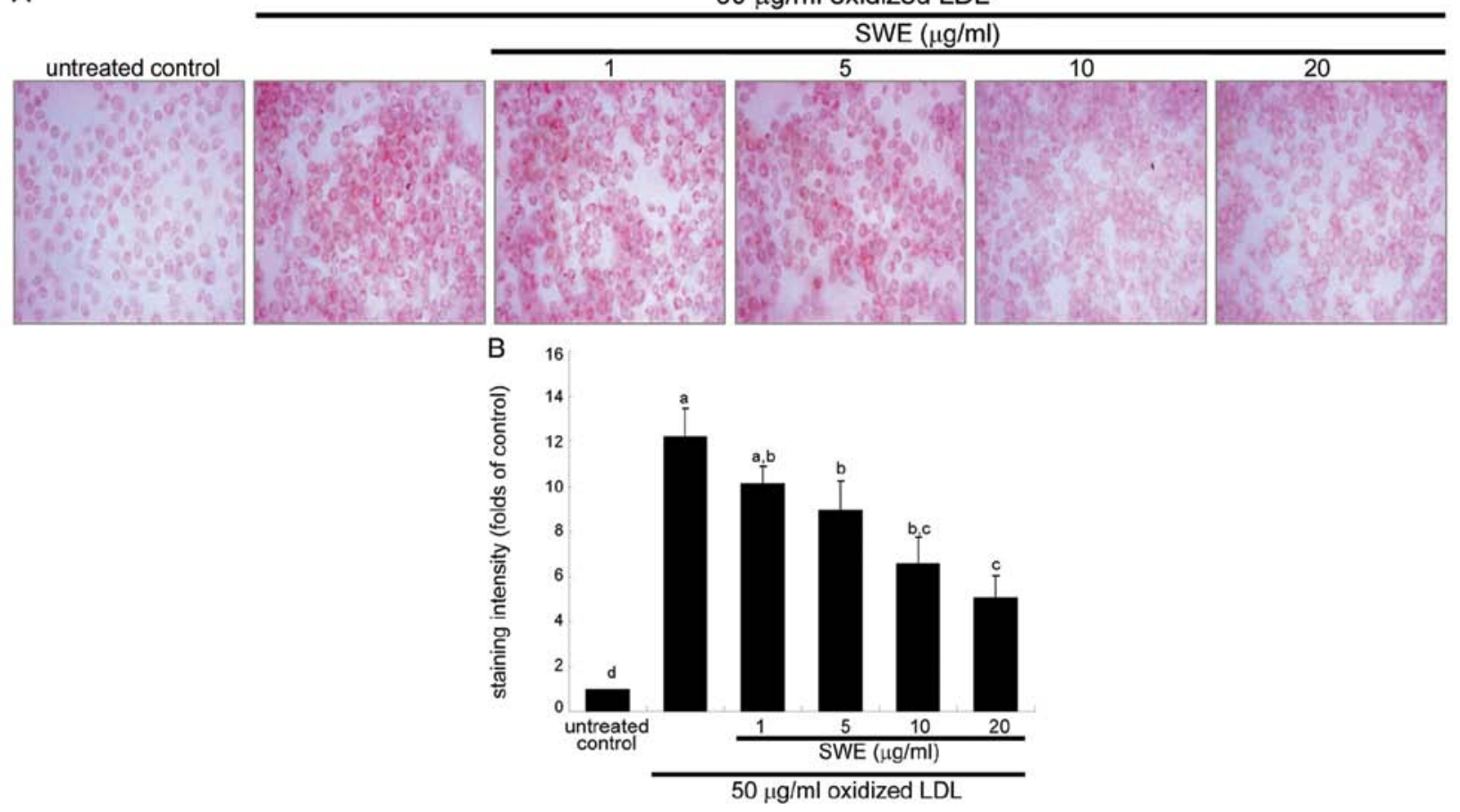

Figure 2. Inhibitory effects of SWE on formation of foam cells. J774A1 macrophages were exposed to $50 \mu \mathrm{g} / \mathrm{ml}$ oxidized LDL for $18 \mathrm{~h}$ in the absence and presence of $1-20 \mu \mathrm{g} / \mathrm{ml}$ SWE. After cells were stained with Oil red O, microphotographs were obtained using an optical microscopy, Magnification x200. Stained cells were dissolved in isopropanol solution and the staining intensity was measured at $490 \mathrm{~nm}$. Data are mean $\pm \mathrm{SEM}, \mathrm{n}=3$. Values in bar graphs not sharing the same letter indicate significant different at $\mathrm{P}<0.05$.
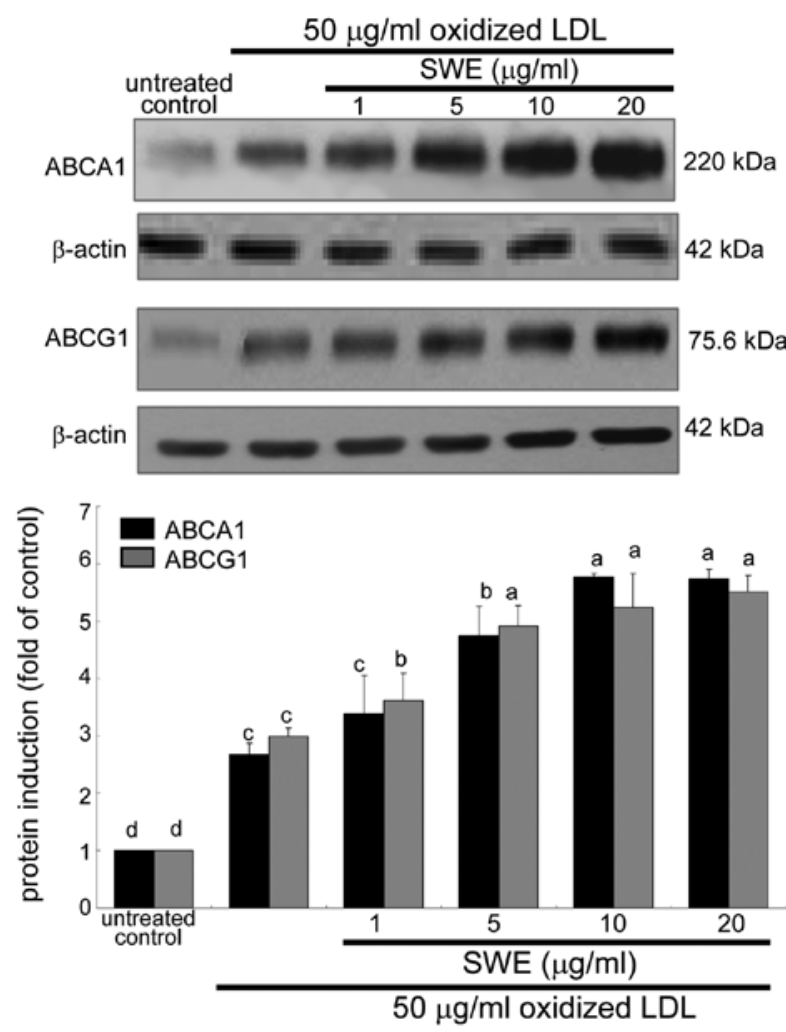

Figure 3. Upregulation of oxidized LDL-induced expression of ABCA1 and ABCG1 by SWE. J774A1 cells were treated with 1-20 $\mu \mathrm{g} / \mathrm{ml}$ SWE for $18-\mathrm{h}$ stimulation with $50 \mu \mathrm{g} / \mathrm{ml}$ oxidized LDL. For the measurement of ABCA1 and ABCG1 expression, total cell lysates were subjected to Western blot analysis with a primary antibody against ABCA1 and ABCG1. $\beta$-actin was used as an internal control. Data are mean $\pm \mathrm{SEM}, \mathrm{n}=3$. Means without a common letter differ at $\mathrm{P}<0.05$.
Effects of SWE on reduction of foam cell formation. This study examined intracellular lipid accumulation in macrophages by using oil red $\mathrm{O}$ staining. There was strong reddish staining observed in macrophages exposed to $50 \mu \mathrm{g} / \mathrm{ml}$ oxidized LDL for $18 \mathrm{~h}$. This indicates cellular accumulation of lipids through the upregulated SR-B1. When $\geq 5 \mu \mathrm{g} / \mathrm{ml} \mathrm{SWE}$ was applied to macrophages for $18 \mathrm{~h}$, reddish lipid droplets disappeared (Fig. 2). Accordingly, SWE delayed foam cell formation in macrophages exposed to $50 \mu \mathrm{g} / \mathrm{ml}$ oxidized LDL.

Enhancement of $A B C A 1$ and $A B C G 1$ expression by SWE. The membrane proteins of ABCA1 and ABCG1 are responsible for cholesterol efflux from lipid-laden macrophages $(6,7)$. The application of $50 \mu \mathrm{g} / \mathrm{ml}$ oxidized LDL to macrophages promoted the expression of ABCA1 and ABCG1 $8 \mathrm{~h}$ after its treatment (data not shown). When $\geq 5 \mu \mathrm{g} / \mathrm{ml} \mathrm{SWE}$ was applied to macrophages exposed to oxidized LDL, the induction of these proteins was further upregulated (Fig. 3). Accordingly, $\geq 5 \mu \mathrm{g} / \mathrm{ml} \mathrm{SWE} \mathrm{may}$ promote cholesterol efflux from lipid-laden foam cells. In addition, the ABCA1 and ABCG1 mRNA levels were elevated within $2 \mathrm{~h}$ in macrophages exposed to $50 \mu \mathrm{g} / \mathrm{ml}$ oxidized LDL, as determined by quantitative RT-PCR assay. The transcription of ABCA1 and ABCG1 was further enhanced in lipid-laden macrophages supplemented with $\geq 10 \mu \mathrm{g} / \mathrm{ml} \mathrm{SWE}$ (Fig. 4).

Acceleration of cholesterol efflux by SWE. It has been shown that cholesterol efflux from macrophages to apoE decreases foam cell formation and prevents atherosclerosis $(8,10)$. This study showed that apoE was secreted from $50 \mu \mathrm{g} / \mathrm{ml}$ oxidized LDL-added macrophages (Fig. 5A). In lipid-laden macrophages 

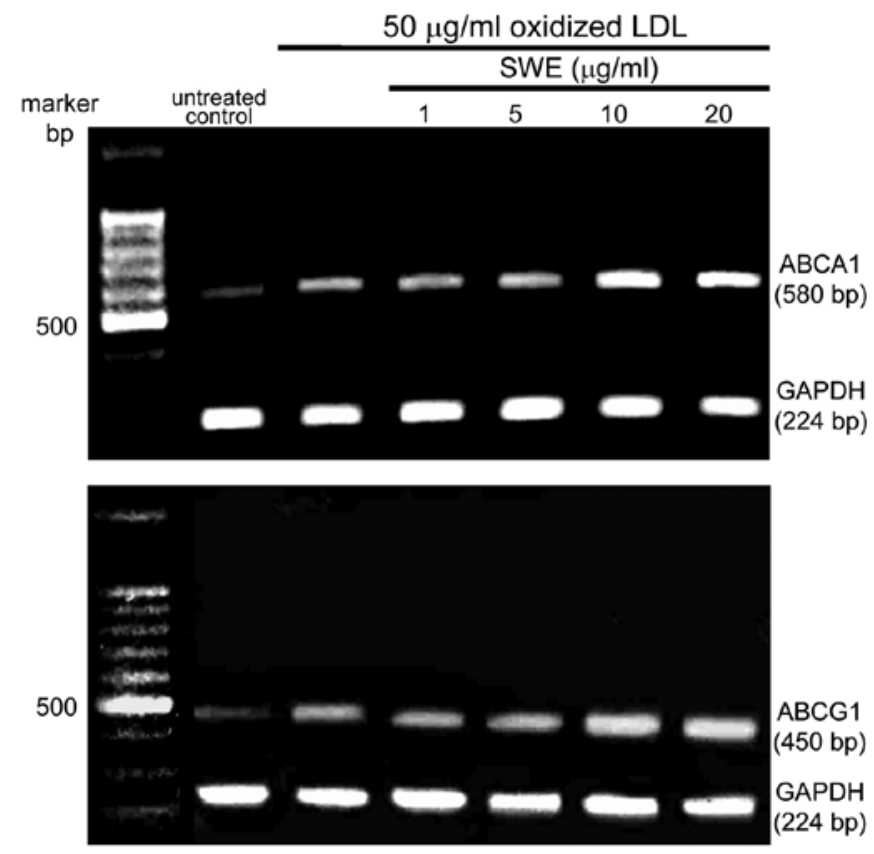

Figure 4. Acceleration of oxidized LDL-induced transcription of ABCA1 and ABCG1 by SWE. J774A1 cells were treated with 1-20 $\mu \mathrm{g} / \mathrm{ml} \mathrm{SWE}$ for $2-\mathrm{h}$ stimulation with $50 \mu \mathrm{g} / \mathrm{ml}$ oxidized LDL. ABCA1 and ABCG1 mRNA transcriptional levels were measured using quantative RT-PCR analysis. GAPDH was used as a housekeeping gene for the co-amplification with ABCA1 and ABCG1. supplemented with $\geq 10 \mu \mathrm{g} / \mathrm{ml} \mathrm{SWE}$, apoE secretion was enhanced at protein levels (Fig. 5A). Thus, it is deemed that $\geq 10 \mu \mathrm{g} / \mathrm{ml} \mathrm{SWE}$ promoted cholesterol efflux through ABCA1 and ABCG1 upregulated by apoE (10).

SWE boosted the induction of ABCA1 and ABCG1 proteins at the transcriptional levels (Fig. 3). Consistently, cholesterol efflux was enhanced in oxidized LDL-treated macrophages (Fig. 5B). The efflux was further accelerated in macrophages exposed to $50 \mu \mathrm{g} / \mathrm{ml}$ oxidized LDL and treated with $\geq 10 \mu \mathrm{g} / \mathrm{ml}$ SWE (Fig. 5B). In addition, the HDL formation was enhanced at levels of protein in lipid-laden macrophages treated with oxidized LDL, which was further highly enhanced by $20 \mu \mathrm{g} / \mathrm{ml}$ SWE (Fig. 5C).

Inhibitory effects of homoplantaginin on uptake of oxidized $L D L$. The SWE application to oxidized LDL-treated macrophages upregulated the cellular expression of ABCA1 and ABCG1 (Fig. 3). This study elucidated whether homoplantaginin and hispidulin, the single compounds present in sage weeds (Fig. 6A), influenced cholesterol efflux from lipid-laden foam cells. Homoplantaginin and hispidulin did not modulate the cellular expression of ABCA1 and ABCG1 upregulated in oxidized LDL-exposed macrophages (Fig. 6B). In contrast, $10 \mu \mathrm{M}$ homoplantaginin, but not hispidulin inhibited SR-B1 induction and consequent uptake of oxidized LDL in J774A.1 macrophages (Fig. 7). These results indicate that SWE containing

A
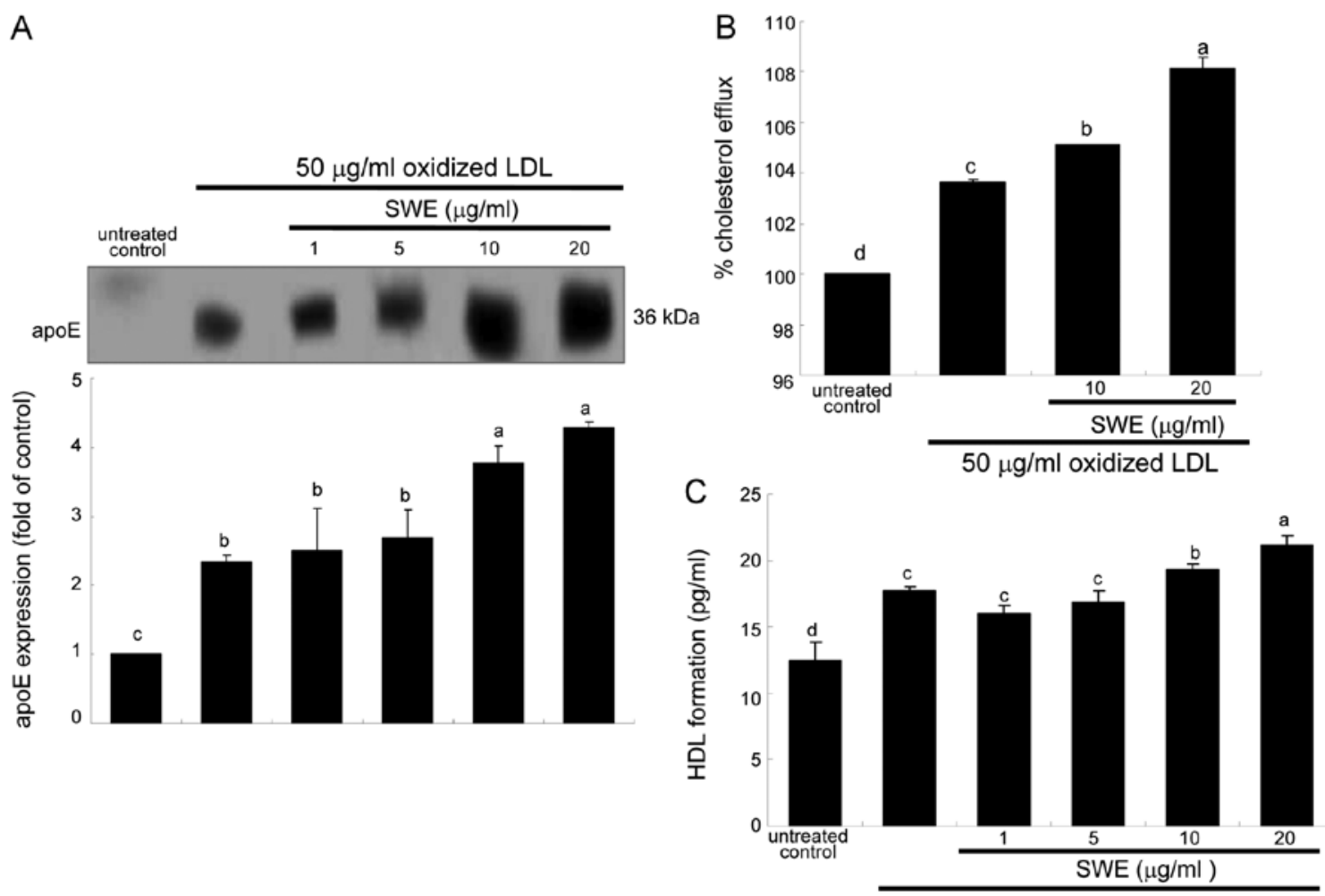

$50 \mu \mathrm{g} / \mathrm{ml}$ oxidized LDL

Figure 5. Enhancement of apoE secretion (A), cholesterol efflux (B) and HDL formation (C) by SWE in lipid-laden foam cells formed by oxidized LDL. Cells were treated with $50 \mu \mathrm{g} / \mathrm{ml}$ oxidized LDL in the absence and presence of 1-20 $\mu \mathrm{g} / \mathrm{ml} \mathrm{SWE}$ for $18-24 \mathrm{~h}$. For the measurement of apoE secretion, media were subjected to Western blot analysis with a primary antibody against apoE. J774A1 macrophages were equilibrated with $1 \mu \mathrm{g} / \mathrm{ml} 3$-dodecanoyl-NBD-labeled cholesterol (B). The fluorescence-labeled cholesterol released from cells into medium for $6 \mathrm{~h}$ was detected by using a fluorometer. Cholesterol efflux was expressed as percent fluorescence in medium relative to untreated control (B). HDL formation was measured by using ELISA kits. The enzyme-substrate reaction was terminated by the addition of $3 \mathrm{~N}$ sulphuric acid solution. The color change was detected spectrophotometrically at $\lambda=450 \mathrm{~nm}$. Data are mean \pm SEM, $\mathrm{n}=3$. Means without a common letter differ at $\mathrm{P}<0.05$. 
<smiles>COc1c(O)cc2oc(-c3ccc(O)cc3)cc(=O)c2c1O</smiles>

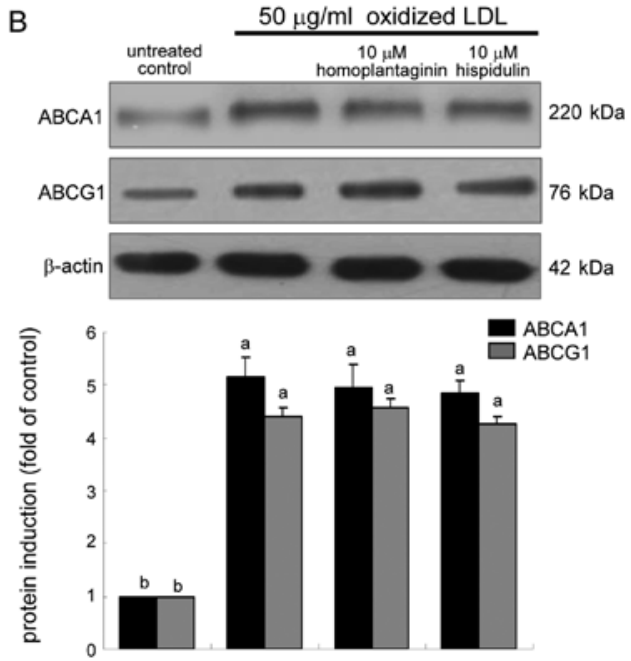

Figure 6. Chemical structure of homoplantaginin and hispidulin (A) and their effects on cellular expression of ABCA1 and ABCG1 (B). J774A.1 cells were treated with $10 \mu \mathrm{M}$ homoplantaginin and hispidulin for $18 \mathrm{~h}$ in the absence and presence of $50 \mu \mathrm{g} / \mathrm{ml}$ oxidized LDL. For the measurement of ABCA1 and ABCG1 expression, total cell lysates were subjected to Western blot analysis with a primary antibody of $\mathrm{ABCA} 1$ and $\mathrm{ABCG} 1 . \beta$-actin was used as an internal control. Data are mean $\pm \mathrm{SEM}, \mathrm{n}=3$. Means without a common letter differ at $\mathrm{P}<0.05$. homoplantaginin retarded foam cell formation as an antiatherogenic agent.

\section{Discussion}

There are five major observations extracted from this study. i) SWE at $\geq 10 \mu \mathrm{g} / \mathrm{ml}$ inhibited SR-B1 expression accounting for oxidized LDL uptake and cellular lipid accumulation in J774A1 murine macrophages. ii) Oxidized LDL enhanced ABCA1 and ABCG1 expression, which was further promoted at transcriptional and protein levels by $\geq 5 \mu \mathrm{g} / \mathrm{ml} \mathrm{SWE}$. iii) SWE accelerated apoE secretion from lipid-laden macrophages. iv) SWE promoted cholesterol efflux and HDL formation through inducing ABCA1 and ABCG1 expression. v) Homoplantaginin but not hispidulin, the single components of sage weeds, alleviated SR-B1 induction and foam cell formation. Accordingly, it is deemed that SWE antagonized foam cell formation in the vascular wall and promoted the export of cholesterol from lipid-laden macrophages to the reverse cholesterol transport. Therefore, SWE may be a therapeutic anti-atherogenic agent in the development of atherosclerosis.

Oxidized LDL uptake, is a key initial event in atherogenesis, steering foam cell formation toward the development of atherosclerosis. Modified LDL is taken up mainly by SR-A and SR-B1 of macrophages (1). Especially the macrophage SR-B1 is responsible for oxidized LDL uptake and facilitates the intracellular accumulation of lipid droplets $(2,18)$. The present study revealed that SWE dampened foam cell formation augmented within $18 \mathrm{~h}$ after treating oxidized LDL. This inhibition was mediated most likely through downregulating SR-B1 induction stimulated by oxidized LDL. Intracellular lipids in the cytoplasm of macrophages are shown to be degraded to
B

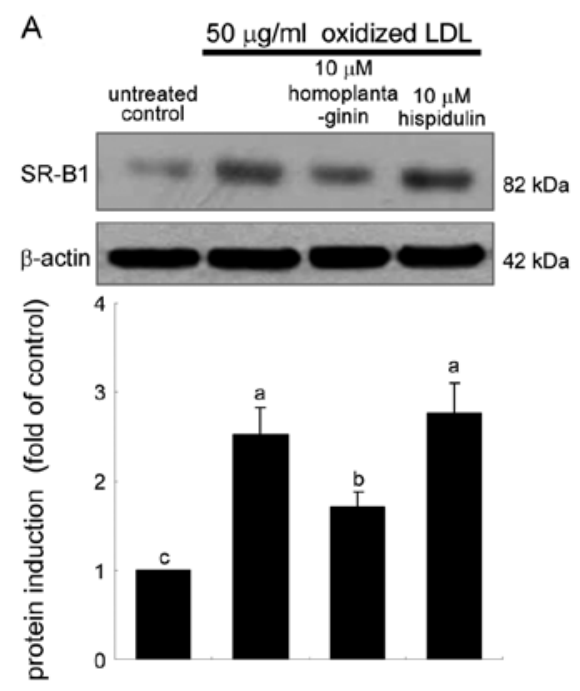

untreated control

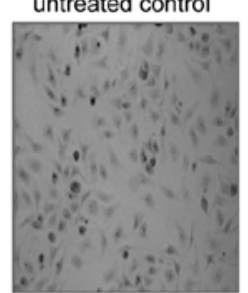

$50 \mu \mathrm{g} / \mathrm{ml}$ oxidized LDL
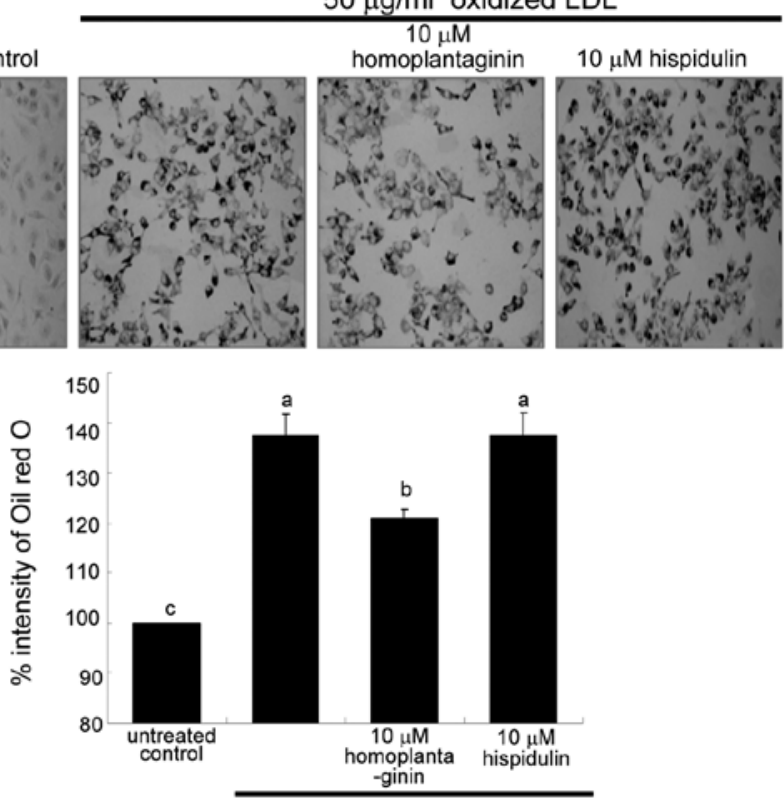

$50 \mu \mathrm{g} / \mathrm{ml}$ oxidized LDL

Figure 7. Attenuation of SR-B1 induction (A) and foam cell formation (B) by homoplantaginin and hispidulin. J774A.1 macrophages were treated with $10 \mu \mathrm{M}$ homoplantaginin and hispidulin in the absence and presence of $50 \mu \mathrm{g} / \mathrm{ml}$ oxidized LDL for $6 \mathrm{~h}$. For the measurement of SR-B1 expression, total cell lysates were subjected to Western blot analysis with a primary antibody of SR-B1 (A). $\beta$-actin was used as an internal control. After culture protocols, macrophages were stained with Oil red $\mathrm{O}$ to measure foam cell formation (B). Microphotographs were obtained using an optical microscopy. Magnification x200. Stained cells were dissolved in isopropanol solution and the staining intensity was measured at $490 \mathrm{~nm}$. Data are mean \pm SEM, $\mathrm{n}=3$. Values in bar graphs not sharing the same letter indicate significant different at $\mathrm{P}<0.05$. 
phospholipids, oxysterols and free cholesterol in the lysosome $(3,19)$. Cytotoxic oxysterols induce macrophage apoptosis and play a central role in promoting atherogenesis with the build-up of atherosclerotic plaques (4,5). Accordingly, SWE is a potential anti-atherogenic agent blunting oxidized LDL uptake leading to production of oxysterols. It should be noted that homoplantaginin may play a role in antagonizing foam cell formation by SWE. The antagonizing activity appeared to require the glucose moiety of homoplataginin. However, the underlying mechanisms by which SWE interrupted oxidized LDL uptake remain to be elucidated. The inhibition of oxidized LDL-induced SR-B1 induction by SWE was achieved at its transcriptional level. Similarly, soy pinitol has inhibitory effects on foam cell formation by reducing lipid accumulation and macrophage SR expression via its insulin-like action (20).

Sage weed as a folk medicine has been investigated for its medicinal properties (11). The ethanol extract of Salvia plebeia possessed anti-inflammatory and anti-angiogenic, anti-nociceptive and antioxidant activities (12). Numerous antioxidant compounds such as royleanonic acid, hispidulin and eupatorin were isolated and identified in crude extract of sage weed (11). Chemical fingerprint and quantitative analysis showed that seven bioactive compounds of homoplantaginin, hispidulin, luteolin, nepetin, caffeic acid, luteolin-7-glucoside, and nepetin7-glucoside contained as constituents in Salvia plebeia (21). The major compound of Salvia plebeia, homoplantaginin, has a protective and therapeutic effect on hepatocyte injury, which might be associated with its antioxidant activity $(21,22)$. Unfortunately, the present study did not identify the constituents of SWE. However, this study found that homoplataginin, a major constituent in Salvia plebeia, inhibited cellular SR-B1 induction and oxidized LDL uptake of lipid-laden macrophages. There have been no reports demonstrating anti-atherogenic activity of SWE and homoplantaginin. It can be speculated that homoplataginin present in sage weeds may exert anti-atherogenic activity dampening SR-B1 induction.

The export of cholesterol and lipids from macrophages is arbitrated by reverse cholesterol transport, the process involving ABCA1 and ABCG1 (6,7). These proteins mediate the movement of cholesterol between cells and extracellular acceptors (23). ABCA1 is responsible for the export of cholesterol and phospholipids to generate precursors for HDL particles $(6,8)$. In addition, ABCG1 mediates oxysterol efflux from oxidized LDL-loaded macrophages (7). Accordingly, the upregulation of ABCA1 and ABCG1 is considered anti-atherogenic. This study showed that SWE further upregulated ABCA1 and ABCG1 of lipid-laden foam cells and elevated cholesterol efflux. Thus, SWE may be a therapeutically athero-protective agent against the development of atherosclerosis. Several studies show that hispidulin, another compound present in Salvia plebeia, exerts anticancer effects and has the potential to be a chemopreventive and therapeutic agent $(24,25)$. Nevertheless, this compound is unknown in the anti-atherogenic activity upregulating cholesterol efflux. This study failed to show promoting effects of homoplantaginin and hispidulin, on ABCA1 expression. However, caffeic acid, one of Salvia plebeia constituents, enhanced cholesterol efflux from THP-1 macrophages mediated by HDL, and induced expression of ABCG1 and SR-BI but not ABCA1 (26). Thus, other unknown components appeared to be responsibe for increasing cholesterol efflux and HDL formation by SWE.
ApoE is essential for the normal catabolism of triglyceriderich lipoprotein constituents. There are numerous studies in regard of apoE-mediated cholesterol efflux. Cholesterol efflux from macrophages to apoE diminishes foam cell formation and prevents atherosclerosis $(9,10)$. However, very little is known about the apoE activity related to cholesterol transporters. Several membrane transporters related to cholesterol efflux include ABCA1, ABCG1, SR-B1 and caveolin-1 (27). A recent study showed that apoE is involved in cholesterol efflux in macrophages by upregulating ABCA1 expression (10). This study showed that SWE was an apoE promoter enhancing its secretion in oxidized LDL-loaded macrophages. This may be an athero-protective mechanism by which SWE boosted ABCA1 expression and cholesterol efflux. Conversely, epigallocatechin3-gallate attenuated downregulated ABCA1 and decreased cholesterol efflux to apoA 1 in TNF- $\alpha$-exposed macrophage foam cells (28).

In conclusion, this study demonstrated that SWE dampened oxidized LDL uptake through reducing SR-B1 expression at a transcriptional level and attenuated foam cell formation full of cholesterol in the cytoplasm of macrophages. Homoplantaginin but not hispidulin, major components of SWE, alleviated foam cell formation by downregulating of SR-B1 induction. In addition, SWE enhanced cholesterol efflux in oxidized LDL-loaded macrophages through further inducing ABCA1 and ABCG1 expression and apoE secretion. Other unknown components in SWE, but not homoplantaginin and hispidulin, appeared to be involved in HDL formation. Therefore, SWE may be a protective agent against atherosclerosis by inhibiting foam cell formation and boosting cholesterol efflux from lipid-laden macrophages.

\section{Acknowledgements}

This study was financially supported by Ministry for Food, Agriculture, Forestry and Fisheries (112085-3), National Research Foundation of Korea (2012012946), and by National Research Foundation of Korea through the Human Resource Training Project for Regional Innovation (2012-01-A-05-00312-010100).

\section{References}

1. Kunjathoor VV, Febbraio M, Podrez EA, Moore KJ, Andersson L, Koehn S, Rhee JS, Silverstein R, Hoff HF and Freeman MW: Scavenger receptors class A-I/II and CD36 are the principal receptors responsible for the uptake of modified low density lipoprotein leading to lipid loading in macrophages. J Biol Chem 77: 49982-49988, 2002.

2. Choi JS, Bae JY, Kim DS, Li J, Kim JL, Lee YJ and Kang YH: Dietary compound quercitrin dampens VEGF Induction and PPAR $\gamma$ activation in oxidized LDL-exposed murine macrophages: Association with scavenger receptor CD36. J Agric Food Chem 58: 1333-1341, 2010.

3. Wen Y and Leake DS: Low density lipoprotein undergoes oxidation within lysosomes in cells. Circ Res 100: 1337-1343, 2007.

4. Shibata N and Glass CK: Macrophages, oxysterols and atherosclerosis. Circ J 74: 2045-2051, 2010.

5. Freeman NE, Rusinol AE, Linton M, Hachey DL, Fazio S, Sinensky MS and Thewke D: Acyl-coenzyme A: cholesterol acyltransferase promotes oxidized LDL/oxysterol-induced apoptosis in macrophages. J Lipid Res 46: 1933-1943, 2005.

6. Chawla A, Boisvert WA, Lee CH, Laffitte BA, Barak Y, Joseph SB, Liao D, Nagy L, Edwards PA, Curtiss LK, Evans RM and Tontonoz P: A PPAR $\gamma$-LXR-ABCA1 pathway in macrophages is involved in cholesterol efflux and atherogenesis. Mol Cell 7: 161-171, 2001. 
7. Xu M, Zhou H, Tan KC, Guo R, Shiu SW and Wong Y: ABCG1 mediated oxidized LDL-derived oxysterol efflux from macrophages. Biochem Biophys Res Commun 390: 1349-1354, 2009.

8. Akiyama TE, Sakai S, Lambert G, Nicol CJ, Matsusue K, Pimprale S, Lee YH, Ricote M, Glass CK, Brewer HB Jr and Gonzalez FJ: Conditional disruption of the peroxisome proliferator-activated receptor gamma gene in mice results in lowered expression of ABCA1, ABCG1, and apoE in macrophages and reduced cholesterol efflux. Mol Cell Biol 22: 2607-2619, 2002.

9. Dove DE, Linton MF and Fazio S: ApoE-mediated cholesterol efflux from macrophages: separation of autocrine and paracrine effects. Am J Physiol Cell Physiol 288: C586-C592, 2005.

10. Zhao Y, Chen X, Yang H, Zhou L, Okoro EU and Guo Z: A novel function of apolipoprotein E: upregulation of ATP-binding cassette transporter A1 expression. PLoS One 6: e21453, 2011.

11. Gu L and Weng X: Antioxidant activity and components of Salvia plebeia R.Br. - a Chinese herb. Food Chem 73: 299-305, 2001.

12. Jung HJ, Song YS, Lim CJ and Park EH: Anti-inflammatory, anti-angiogenic and anti-nociceptive activities of an ethanol extract of Salvia plebeia R. Brown. J Ethnopharmacol 126 : 335-360, 2009

13. Lim JA, Yun BW and Baek SH: Antioxidative activity and nitrite scavenging ability of methanol extract from Salvia plebeia $\mathrm{R}$. Br. Korean J Med Crop Sci 15: 183-188, 2007.

14. Choi JS, Kang SW, Li J, Kim JL, Bae JY, Kim DS, Shin SY, Jun JG, Wang MH and Kang YH: Blockade of oxidized LDL-triggered endothelial apoptosis by quercetin and rutin through differential signaling pathways involving JAK2. J Agric Food Chem 57: 2079-2086, 2009.

15. Lowry OH, Rosebrough NJ, Farr AL and Randall RJ: Protein measurement with the Folin phenol reagent. J Biol Chem 193: 265-275, 1951

16. Jeong YJ, Choi YJ, Choi JS, Kwon HM, Kang SW, Bae JY, Lee SS, Kang JS, Han SJ and Kang YH: Attenuation of monocyte adhesion and oxidised LDL uptake in luteolin-treated human endothelial cells exposed to oxidised LDL. Br J Nutr 97: 447-457, 2007.

17. Kang SW, Choi JS, Bae JY, Li J, Kim DS, Kim JL, Shin SY, You HJ, Park HS, Ji GE and Kang YH: Blockade of vascular angiogenesis by Aspergillus usamii var. shirousamii-transformed Angelicae Gigantis Radix and Zizyphus jujuba. Nutr Res Pract 3: 3-8, 2009.

18. Endemann G, Stanton LW, Madden KS, Bryant CM, White RT and Protter AA: CD36 is a receptor for oxidized low density lipoprotein. J Biol Chem 268: 11811-11816, 1993.
19. Li W, Yuan XM, Olsson AG and Brunk UT: Uptake of oxidized LDL by macrophages results in partial lysosomal enzyme inactivation and relocation. Arterioscler Thromb Vasc Biol 18: 177-184, 1998.

20. Choi MS, Lee WH, Kwon EY, Kang MA, Lee MK, Park YB and Jeon SM: Effects of soy pinitol on the pro-inflammatory cytokines and scavenger receptors in oxidized low-density lipoprotein-treated THP-1 macrophages. J Med Food 10: 594-601, 2007.

21. Jin XF, Lu YH, Wei DZ and Wang ZT: Chemical fingerprint and quantitative analysis of Salvia plebeia $\mathrm{R}$.Br. by highperformance liquid chromatography. J Pharm Biomed Anal 48: 100-104, 2008

22. Qu XJ, Xia X, Wang YS, Song MJ, Liu LL, Xie YY, Cheng YN, Liu XJ, Qiu LL, Xiang L, et al: Protective effects of Salvia plebeia compound homoplantaginin on hepatocyte injury. Food Chem Toxicol 47: 1710-1715, 2009.

23. Oqura M, Ayaori M, Terao Y, Hisada T, Iizuka M, Takiquchi S, Uto-Kondo H, Yakushiji E, Nakaya K, Sasaki M, et al: Proteasomal inhibition promotes ATP-binding cassette transporter A1 (ABCA1) and ABCG1 expression and cholesterol efflux from macrophages in vitro and in vivo. Arterioscler Thromb Vasc Biol 31: 1980-1987, 2011.

24. Lin YC, Hung CM, Tsai JC, Lee JC, Chen YL, Wei CW, Kao JY and Way TD: Hispidulin potently inhibits human glioblastoma multiforme cells through activation of AMP-activated protein kinase (AMPK). J Agric Food Chem 58: 9511-9517, 2010.

25. He L, Wu Y, Lin L, Wang J, Wu Y, Chen Y, Yi Z, Liu M and Pang X: Hispidulin, a small flavonoid molecule, suppresses the angiogenesis and growth of human pancreatic cancer by targeting vascular endothelial growth factor receptor 2-mediated PI3K/ Akt/mTOR signaling pathway. Cancer Sci 102: 219-225, 2011.

26. Uto-Kondo H, Ayaori M, Ogura M, Nakaya K, Ito M, Suzuki A Takiguchi S, Yakushiji E, Terao Y, Ozasa $\mathrm{H}$, et al: Coffee consumption enhances high-density lipoprotein-mediated cholesterol efflux in macrophages. Circ Res 106: 779-787, 2010.

27. Tall AR: Cholesterol efflux pathways and other potential mechanisms involved in the athero-protective effect of high density lipoproteins. J Intern Med 263: 256-273, 2008.

28. Jiang J, Mo ZC, Yin K, Zhao GJ, Lv YC, Ouyang XP, Jiang ZS, $\mathrm{Fu} Y$ and Tang CK: Epigallocatechin-3-gallate prevents TNF- $\alpha$ induced NF- $\mathrm{KB}$ activation thereby upregulating $\mathrm{ABCA} 1$ via the Nrf2/Keap1 pathway in macrophage foam cells. Int J Mol Med 29: 946-956, 2012. 